\title{
10-Year Performance of Veneered CAD/CAM versus Conventional Single-Span and Multi-Span Fixed Partial Dentures
}

\author{
Silvia Brandt ${ }^{1^{\star}}$, Jan-Tobias Süss ${ }^{2}$, Hans-Christoph Lauer ${ }^{1}$ and Jan Brandt ${ }^{1}$ \\ ${ }^{1}$ Department of Prosthodontics, Goethe University Frankfurt, Germany \\ ${ }^{2}$ Dentist Privat Practice, Büdingen Alter Weg 9, 63225 Langen, Germany
}

"Corresponding author: Dr. Silvia Brandt, Associate Professor, Department of Prosthodontics, ZZMK Carolinum, Goethe University, Frankfurt, Theodor-Stern-Kai 7, Haus 29, 60596 Frankfurt am Main, Germany, Tel: +49696301 83617; Fax: +49696301 3711; E-mail: hajjaj@med.uni-frankfurt.de

Received date: July 03, 2017; Accepted date: July 12, 2017; Published date: July 20, 2017

Copyright: @ 2017 Brandt S, et al. This is an open-access article distributed under the terms of the Creative Commons Attribution License, which permits unrestricted use, distribution, and reproduction in any medium, provided the original author and source are credited.

\begin{abstract}
Aim: The aim of the present study was to compare the survival rates of different materials for fixed partial dentures (FPDs).

Materials and Methods: A total of 547 FPDs made of different materials delivered to 319 patients were studied retrospectively with a mean observation time of 9.3 years. Cast-metal, metal-ceramic, and all-ceramic FPDs were included in the study and compared.

Results: The 10-year survival rate for cast-metal FPDs was 92.7\%, for metal-ceramic FPDs, 76.2\%, and for allceramic FPDs, $88.2 \%$. No significant findings were reported regarding FPD materials and long-term survival rates.

Conclusion: Unlike in previous studies, no significant difference between the survival rates of all-ceramic FPDs and FPDs made of other materials was found. These results may be due to modern manufacturing methods of FPD frameworks - in particular CAD/CAM technology, which facilitates optimized framework designs.
\end{abstract}

Keywords: Long term survival rates fixed partial dentures; Castmetal-ceramic fixed partial dentures; All-ceramic fixed partial dentures; Cast-metal fixed partial dentures; CAD/CAM framework

\section{Introduction}

The adequate replacement of lost or congenitally missing teeth is an important part of every dentist's daily routine. Even though the number of missing teeth in German adults between 35 and 44 years of age is declining [1], many of the resulting edentulous spaces are rehabilitated using a bridge restoration (fixed partial denture, FPD). The teeth most frequently replaced by FPDs are the maxillary premolars and the maxillary and mandibular first molars. Most of these FPDs are delivered when the patients are between 31 and 50 years old [2].

Notwithstanding the growing popularity of oral implantology, not every patient can receive an implant-supported rehabilitation. The comparative advantages and disadvantages of implant-supported restorations and conventional bridges must be individually evaluated for each patient and the patient treated accordingly [3]. For this reason, the restoration of edentulous spaces gap supply by means of conventional tooth-supported bridges will continue to play an important role in dental therapy in the future. Therapeutic alternatives in the form of removable dentures, orthodontic space closure, or no treatment will not be discussed at this point.

Numerous studies on FPDs have shown that properly delivered restorations of this type can achieve high levels of patient satisfaction and very good long-term results [4-10].
To obtain these desirable long-term outcomes, it is essential to evaluate the abutment teeth before prescribing an FPD. Factors such as the number, shape and distribution of roots, the height and width of the crown, the length ratio between root and crown, but also any tooth mobility or possible bone loss play an important role [11]. A conscientious assessment of the abutment teeth and the consultation of scientific studies on the survival of various restorative options [12] provide invaluable and indispensable input for the subsequent treatment-planning stage.

Sailer and coworkers examined 1,163 metal-ceramic (MC) FPDs and 343 all-ceramic (AC) FPDs. The 5-year success rates of $94.4 \%$ (MC) and $88.6 \%(\mathrm{AC})$ were significantly different, which according to Sailer and coworkers is due to the increased susceptibility to framework and veneer fracture in all-ceramic FPDs. The use of zirconia was to have reduced these technical shortcomings significantly [4]. Comparable results were obtained by Beuer and coworkers, who found a survival rate of $90.5 \%$ for 21 all-ceramic FPDs after 40 months [5]. Pjetursson and Lang examined possible differences in survival rates of different types of FPD in a systematic review. For conventional FPD, they found survival rates of $93.8 \%$ and $89.2 \%$ after 5 and 10 years, respectively. These survival rates were higher than those for cantilever bridges ( $91.4 \%$ and $80.3 \%$ after 5 and 10 years) and adhesive bridges (87.7\% 65\% after 5 and 10 years) [6]. Re-reading the study by Kantorowicz (1968), it is interesting to see that the survival rates cited for 149 FPDs, at $85 \%$ after 10 years, are of the same magnitude as the results of today's studies [13].

Then as now, there are several possible complications that can lead to a failure of a bridge restoration. These include secondary caries, 
endodontic complications, periodontal reactions, damage to the ceramic veneer (chipping), and decementation of the restoration.

The literature shows that the survival rates are significantly lower for AC than for MC [4]. These findings were to be followed up retrospectively as a facet within the development of a therapeutic concept for bridge restorations conducted at the Center for Oral and Maxillofacial Surgery (ZZMK Carolinum) at the University of Frankfurt am Main over a period of 10 years. In addition, the longterm success rates determined for different FPD materials were to be evaluated in the context of the current literature on the subject.

\section{Method and Materials}

The data evaluated in this study originate in the medical records of the Center for Oral and Maxillofacial Surgery (ZZMK Carolinum) at the University of Frankfurt am Main, Germany. Analyzing the electronic accounting records of individual billable services rendered, patients were identified who had received a tooth-supported FPD since 2002. The specific inclusion criteria were:

- Fabrication and delivery of the restoration at the ZZMK

- Natural teeth as abutments only

- Definitive FPD rehabilitation

- For AC: zirconia frameworks with ceramic veneering only

- Clearly documented location of the restoration

Taking into account the above criteria, a total of 547 FPD in 319 patients, treated by dentists and students of the dental school, were examined. During the subsequent evaluation of the patient records, the following parameters were studied:

- Age and gender

- Frequency of recalls

- Medical practitioner (dentist or student)

- Location of the FPD

- Single-span or multi-span FPD

- Cantilever or terminal FPD

- Abutment vitality

- Opposing dentition

- Type of FPD

- Type of complication

- Differentiation between reparable and irreparable damage

- Treatment of complications

- Necessary extractions

In the event that complications were recorded in the medical history, they were further subdivided into:

\section{Biological complications}

- Secondary caries

- Apical osteitis

- Horizontal and vertical bone loss (periodontitis)

- Root fractures

- Enamel fractures

\section{Technical complications}

- Damage to the ceramic veneer (chipping)

- Decementation

- Framework fractures

- Esthetic deficiencies

All investigated FPD's were fabricated in the same dental laboratory according to the manufacturer instructions with an anatomical shape. The frameworks of the AC's were fabricated by using the CAD-CAM method and were milled out of zirconia (Lava 3M Espe, Seefeld; Cercon DeguDent, Hanau).

The casts of the MC's were manufactured out of metal-alloy (DeguDent Herador, Hanau). Both, the AC and MC frameworks were designed and produced with an anatomical shape to ensure a ceramical veneering (Cercon Kiss, Degudent Hanau) with a thickness of $1 \mathrm{~mm}$ to $1.5 \mathrm{~mm}$. For cementation of the FPD's zinc oxide phosphate cement or glass ionomer cement (Ketac Cem 3M Espe, Seefeld) was used.

To extract the corresponding survival rates from the data, a statistical analysis using the Kaplan-Meier method was performed. Here, the survival rate is represented as a function of time at risk. Significant differences in survival rates between individual groups were analyzed using the Wilcoxon test. The log rank test was used to determine the impact of specific parameters on success rates. A confidence interval of $95 \%$ was adopted for all statistical calculations, which means a statistical significance for $\mathrm{p} \leq 0.05$. The analysis was performed with BiAS 9.14 software packages (IBM).

\section{Result}

A total of 547 FPDs-34 cast-metal (CM), $425 \mathrm{MC}, 88 \mathrm{AC}$ - with a median observation time of 9.3 years were examined retrospectively. Of these, 316 restorations were supported by vital abutment teeth only, 169 by combination of vital and non-vital abutment teeth, and 33 by non-vital abutment teeth only.

Table 1 shows the designs, success rates, and associated complications individual FPDs in detail.

\begin{tabular}{|l|l|l|l|l|l|l|l|l|}
\hline FPD designs & $\begin{array}{l}\text { Cast metal } \\
\text { (CM) }\end{array}$ & $\%$ & $\begin{array}{l}\text { Metal-ceramic } \\
\text { (MC) }\end{array}$ & $\%$ & $\begin{array}{l}\text { All-ceramic } \\
\text { (AC) }\end{array}$ & $\%$ & Total & $\%$ \\
\hline FPDs & 34 & $100.00 \%$ & 425 & $100.00 \%$ & 88 & $100.00 \%$ & 547 & $100.00 \%$ \\
\hline Terminal FPDs & 34 & $100.00 \%$ & 368 & $86.50 \%$ & 76 & $86.40 \%$ & 478 & $87.39 \%$ \\
\hline Cantilever FPDs & 0 & $0.00 \%$ & 57 & $13.40 \%$ & 12 & $13.60 \%$ & 69 & $12.61 \%$ \\
\hline Single-span FPDs & 34 & $100.00 \%$ & 395 & $92.90 \%$ & 7 & $8.00 \%$ & 436 & $79.71 \%$ \\
\hline Multi-span FPDs & 0 & $0.00 \%$ & 30 & $7.10 \%$ & 81 & $92.00 \%$ & 111 & $20.29 \%$ \\
\hline
\end{tabular}


Page 3 of 5

\begin{tabular}{|c|c|c|c|c|c|c|c|c|}
\hline Abutment teeth & 68 & $100.00 \%$ & 950 & $100.00 \%$ & 186 & $100.00 \%$ & 1204 & $100.00 \%$ \\
\hline Vital & 62 & $91.10 \%$ & 747 & $78.60 \%$ & 142 & $76.30 \%$ & 951 & $78.99 \%$ \\
\hline Non-vital & 6 & $8.80 \%$ & 203 & $21.40 \%$ & 44 & $23.70 \%$ & 253 & $21.01 \%$ \\
\hline Of which with post-and-cores & 2 & $33.00 \%$ & 78 & $38.40 \%$ & 24 & $54.50 \%$ & 104 & $41.11 \%$ \\
\hline \multicolumn{9}{|l|}{ Success rates } \\
\hline 5 years without complications & & $93.50 \%$ & & $82.70 \%$ & & $78.20 \%$ & & $0.00 \%$ \\
\hline 10 years without complications & & $84.20 \%$ & & $66.70 \%$ & & $73.10 \%$ & & $60.26 \%$ \\
\hline 5 -year survival rate & & $96.70 \%$ & & $90.80 \%$ & & $95.30 \%$ & & $80.34 \%$ \\
\hline 10-year survival rate & & $92.70 \%$ & & $76.20 \%$ & & $88.20 \%$ & & $69.28 \%$ \\
\hline Mean survival time (years) & 20.2 & & 18.2 & & 12.2 & & 10.6 & \\
\hline \multicolumn{9}{|l|}{ Complications } \\
\hline Insufficient restoration margins & 8 & $23.50 \%$ & 58 & $13.60 \%$ & 3 & $3.40 \%$ & 69 & $12.61 \%$ \\
\hline Apical osteitis & 2 & $5.80 \%$ & 22 & $5.20 \%$ & 1 & $1.10 \%$ & 25 & $4.57 \%$ \\
\hline Root fractures & 2 & $5.80 \%$ & 2 & $0.50 \%$ & 1 & $1.10 \%$ & 5 & $0.91 \%$ \\
\hline Framework fractures & 1 & $2.90 \%$ & 6 & $1.40 \%$ & 4 & $4.50 \%$ & 11 & $2.01 \%$ \\
\hline Chipping & 0 & $0.00 \%$ & 22 & $5.20 \%$ & 2 & $2.30 \%$ & 24 & $4.39 \%$ \\
\hline Decementation/loss of retention & 1 & $2.90 \%$ & 8 & $1.90 \%$ & 14 & $15.90 \%$ & 23 & $4.20 \%$ \\
\hline Perio-endo lesion & 0 & $0.00 \%$ & 1 & $0.20 \%$ & 0 & $0.00 \%$ & 1 & $0.18 \%$ \\
\hline $\begin{array}{l}\text { Enamel fracture of the clinical } \\
\text { crown }\end{array}$ & 0 & $0.00 \%$ & 2 & $0.50 \%$ & 1 & $1.10 \%$ & 3 & $0.55 \%$ \\
\hline Esthetic failure & 0 & $0.00 \%$ & 2 & $0.50 \%$ & 0 & $0.00 \%$ & 2 & $0.37 \%$ \\
\hline Extraction of abutment teeth & 2 & $3.00 \%$ & 39 & $4.10 \%$ & 7 & $0.50 \%$ & 48 & $3.99 \%$ \\
\hline Total failure on average (years) & 13.2 & & 7.3 & & 3 & & 2.8 & \\
\hline
\end{tabular}

Table 1: Individual FPD types: designs, success rates, and associated complications.

The investigated cohort was $56 \%$ female and $44 \%$ male and had no statistical influence on the failure-rate. The age distribution is shown in Figure 1. A statistical significance for a higher risk of FPD failure was found in the group of 70 years and older $(\mathrm{p}=0.001)$. Further no influence of the jaw location or the medical practitioner could be found. The FPD's were located all over in the upper or lower jaw, molar-, premolar- or frontal region.

A closer look only showed a statistical significant higher risk for failure for AC FPD's in the upper jaw if frontal, premolar and molar teeth were included $(\mathrm{p}=0.01)$. In the subsequent analysis of the impact of individual parameters on the success rate of an FPD, no statistically significant correlation could be demonstrated between FPD materials and success rates $(\mathrm{p}=0.55)$, despite the differences in survival rates (Table 1) could be detected.

Figure 2 shows the Kaplan-Meier survival plot. Regarding the differentiation of single-span vs. multi-span FPD, a significantly higher risk of failure was found for multi-span $\mathrm{AC}(\mathrm{p}=0.02)$ are detected. Although the failure rate of all multi-span MC was $13.3 \%$, no statistical significance could be deduced $(\mathrm{p}=0.53)$. However, cantilever AC exhibited a significantly higher risk of failure than terminal AC $(p=0.02)$. Looking at the impact abutment tooth vitality on the success rate, a significant difference was found as soon as two or more abutment teeth were non-vital ( $\mathrm{p}=0.01$ ). In $40 \%$ of cases, an abutment tooth was lost completely during the observation period. If one or more of these abutment teeth had additionally been restored with a post-and-core, the risk of failure increased further $(\mathrm{p}=0.009)$.

Another striking finding of this study was related to AC with $\mathrm{CM}$ as antagonists $(n=2)$, where fracture of the ceramic framework of the FPDs occurred after 116 and 169 days, respectively $(p=0)$. A final special aspect was revealed when looking at the correlation between regular follow-up visits and the failure rate of restorations. If recall appointments were missed, the risk of complications was significantly greater $(\mathrm{p}=0.004)$. 


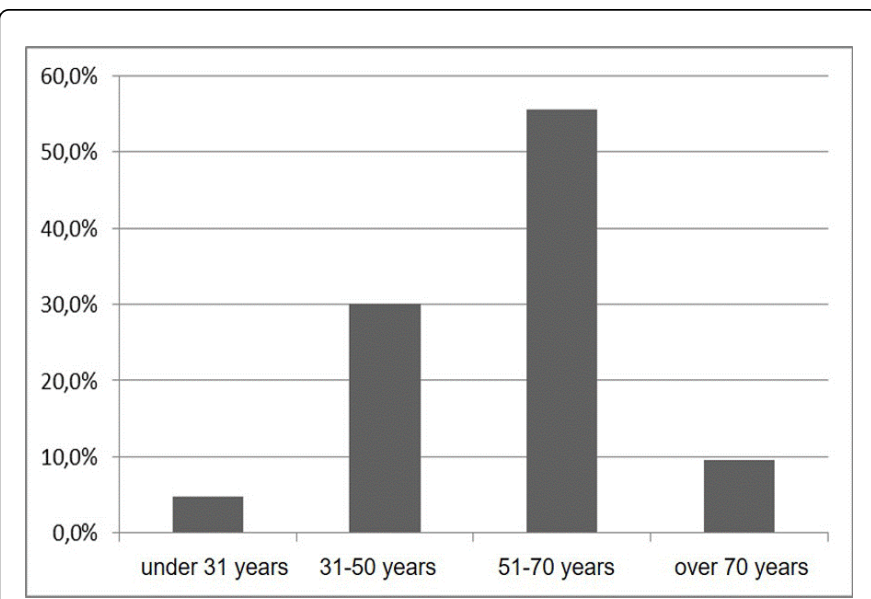

Figure 1: Age distribution.

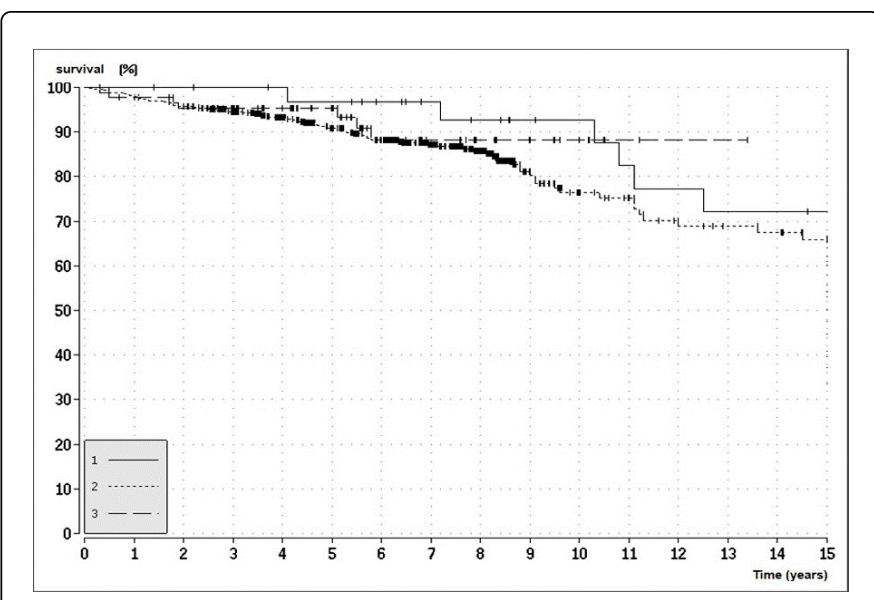

Figure 2: Kaplan-Meier-Plot. Survival rate of CM (1), MC (2), AC (3).

\section{Discussion}

Comparable studies examining the survival rates of FPD designs often did not differentiate between different FPD materials. However, considering the results obtained here, this should not impair comparability with those studies, because the present study- unlike in the study by Sailer and coworkers [4] - was unable to demonstrate a significance correlation between success rates and FPD materials.

Burke and Lucarotti reported a success rate of $72 \%$ after an observation period of 10 years [7]; Izikowitz, 83\% [14], Kerschbaum and coworkers, $82 \%$ [10]; Creugers and coworkers, 90\% [8]; and Pjetturson and Lang, $89.2 \%$ [6]. Comparing the above values with the results of the present study (76-93\%), all the survival rates are within a similar range. The 10 -year survival rate of $92.9 \%$ reported by Lulic and coworkers is also still within this range. In addition, Lulic and coworkers underscored the importance of regular recalls [9]. The positive influence of consistent recalls on the longevity of a prosthetic restoration as demonstrated by this study was confirmed by Kanno and coworkers [15].
The increased risk of failure where FPDs were supported by two or more non-vital abutment teeth had already been discussed by Leempoel and coworkers. They, too, cited considerably less favorable prognoses for restorations on non-vital abutment teeth [16]. De Backer and coworkers [19] showed a still significantly higher risk of non-vital teeth restored with post-and-cores. The reasons for the less favorable outcomes of endodontically treated teeth lie not so much in the prosthetic treatment as in the complications and sequelae of the endodontic treatment itself. According to Elemam and Pretty, the success rate of primary endodontic treatment is about $86 \%$ [17]. Looking at the additional effect of placing an endodontic post, possible complications such as a fracture or debonding of the pin [18] must be taken into account, which can adversely affect the success rate.

Missing reference values prevented a statistical evaluation of the design principles of terminal and cantilever FPD for CM and MC, making this comparison possible for AC only. The observed increased failure rate of cantilever vs terminal FPD corroborates the results of other studies $[19,20]$; it can be mainly explained by the effects of unfavorable leverage on the abutment teeth.

The literature provides no data on potentially increased failure rates of multi-span bridges, which prevents any comparison with previous studies. One possible explanation might be found in the manufacturing process (for example the definition of a common path of insertion) and the increased per cent likelihood of complications due to the greater number of abutment teeth.

But this latter point, too, must be viewed critically given the absence of comparative figures. While the observations related to framework fractures in $\mathrm{AC}$ with $\mathrm{CM}$ in the opposing jaw are significant from a purely statistical point of view, the question remains whether this would not also have been the case in the presence of other types of restorations in the opposing jaw. Other possible reasons may be associated with parafunction, which is another reason why this last point cannot be definitively resolved.

In summary it can be concluded that, compared to the results of Sailer and coworkers [4], the survival rates for AC were higher than those for MC. Thanks to modern materials and manufacturing processes, such as the CAD/CAM technology, using high-performance ceramics and ensuring compliance with the manufacturer's instructions, no significant drawbacks were found in terms of longterm survival. The hypothesis of Sailer and coworkers as initially mentioned - namely that the failure rate of AC could be significantly reduced by using zirconia frameworks [4]- was therefore corroborated. With consistent application of this insight, it should be possible to make AC significantly less prone to complications in daily clinical practice.

\section{Acknowledgments}

The authors report no conflicts of interest related to this study.

\section{References}

1. Schutzhold S, Holtfreter B, Hoffmann T, Kocher T, Micheelis W (2013) Trends in dental health of 35- to 44-year-olds in West and East Germany after reunification. J Public Health Dent 73: 65-73.

2. Leempoel PJ, Rossum GMV, Haan AFD, Reintjes AG (1989) Bridges in general dental practices: a descriptive study of the types of bridges and patients. J Oral Rehabil 16: 381-386.

3. Hebel K, Gajjar R, Hofstede T (2000) Single-tooth replacement: bridge vs. implant-supported restoration. J Can Dent Assoc 66: 435-438. 
Citation: Brandt S, Süss JT , Lauer HC, Brandt J (2017) 10-Year Performance of Veneered CAD/CAM versus Conventional Single-Span and Multi-Span Fixed Partial Dentures. Dentistry 7: 442. doi:10.4172/2161-1122.1000442

Page 5 of 5

4. Sailer I, Pjetursson BE, Zwahlen M, Hammerle CH (2007) A systematic review of the survival and complication rates of all-ceramic and metalceramic reconstructions after an observation period of at least 3 years. Part II: Fixed dental prostheses. Clin Oral Implants Res 18: 86-96.

5. Beuer F, Edelhoff D, Gernet W, Sorensen JA (2009) Three-year clinical prospective evaluation of zirconia-based posterior fixed dental prostheses (FDPs). Clin Oral Investig 13: 445-451.

6. Pjetursson BE, Lang NP (2008) Prosthetic treatment planning on the basis of scientific evidence. J Oral Rehabil 35: 72-79.

7. Burke FJ, Lucarotti PS (2012) Ten year survival of bridges placed in the General Dental Services in England and Wales. J Dent 40: 886-895.

8. Creugers NH, Kayser AF, van't Hof MA (1994) A meta-analysis of durability data on conventional fixed bridges. Community Dent Oral Epidemiol 22: 448-452.

9. Lulic M, Bragger U, Lang NP, Zwahlen M, Salvi GE (2007) Ante's (1926) law revisited: a systematic review on survival rates and complications of fixed dental prostheses (FDPs) on severely reduced periodontal tissue support. Clin Oral Implants Res 18: 63-72.

10. Kerschbaum T, Haastert B, Marinello CP (1996) Risk of debonding in three-unit resin-bonded fixed partial dentures. J Prosthet Dent 75: 248-253.

11. Ikai H, Kanno T, Kimura K (2006) A review of clinical follow-up studies focusing on pretreatment conditions of abutment and clinical examination parameters. Nihon Hotetsu Shika Gakkai Zasshi 50: 245-255.

12. Scheuber S, Hicklin S, Bragger U (2012) Implants versus short-span fixed bridges: survival, complications, patients' benefits. A systematic review on economic aspects. Clin Oral Implants Res 23: 50-62.
13. Kantorowicz GF (1968) Bridges: an analysis of failures. Dent Pract Dent Rec 18: 176-178.

14. Izikowitz L (1976) A long-term prognosis for the fixed saddle-bridge. A study of 100 constructions. J Oral Rehabil 3: 25-40.

15. Kanno T, Nakamura K, Hayashi E, Kimura K, Hirooka H, et al. (2008) What prosthodontic therapy should we select for periodontally compromised patients? Part 2: Review of the literature focusing on conventional prosthodontic therapy for periodontally compromised patients and clinical implication (RPD vs FPD vs implant). Nihon Hotetsu Shika Gakkai Zasshi 52: 143-149.

16. Leempoel PJ, Kayser AF, Van Rossum GM, De Haan AF (1995) The survival rate of bridges. A study of 1674 bridges in 40 Dutch general practices. J Oral Rehabil 22: 327-330.

17. Elemam RF, Pretty I (2011) Comparison of the success rate of endodontic treatment and implant treatment. ISRN Dent 2011: 640509.

18. Soares CJ, Valdivia AD, da Silva GR, Santana FR, Menezes Mde S (2012) Longitudinal clinical evaluation of post systems: a literature review. Braz Dent J 23: 135-740.

19. De Backer H, Van Maele G, Decock V, Van den Berghe L (2007) Longterm survival of complete crowns, fixed dental prostheses, and cantilever fixed dental prostheses with posts and cores on root canal-treated teeth. Int J Prosthodont 20: 229-234.

20. Walls AW (2010) Cantilever FPDs have lower success rates than end abutted FPDs after 10-years of follow-up. J Evid Based Dent Pract 10: 41-43. 